CLINICAL STUDY

\title{
Normalization of catecholamine production following resection of phaeochromocytoma positively influences carotid vascular remodelling
}

Giampaolo Bernini ${ }^{1}$, Fabio Galetta ${ }^{1}$, Ferdinando Franzoni $^{1}$, Michele Bardini ${ }^{1}$, Chiara Taurino ${ }^{1}$, Angelica Moretti $^{1}$ Matteo Bernini ${ }^{1}$, Piero Berti ${ }^{2}$, Paolo Miccoli ${ }^{2}$ and Antonio Salvetti ${ }^{1}$

Departments of ${ }^{1}$ Internal Medicine and ${ }^{2}$ Surgery, University of Pisa, Via Roma 67, 56126 Pisa, Italy

(Correspondence should be addressed to G Bernini; Email: g.bernini@med.unipi.it)

\begin{abstract}
Objective: To evaluate the influence of plasma catecholamines on the vascular structure in humans, the effects of catecholamine normalization on the carotid wall of patients with phaeochromocytoma (PHEO) were investigated. A prospective study in patients with PHEO before and after (first follow-up: $20.5 \pm 1.8$ months, second follow-up: $31.5 \pm 2.2$ months) successful surgery was conducted in the University Referral Center for Blood Pressure Diseases. Ten consecutive patients with PHEOs and ten age- and blood pressure-matched controls were investigated. Intima-media thickness (IMT) by twodimensional conventional ultrasonography and corrected ultrasonic integrated backscatter signal (C-IBS) analysis of carotid arteries were investigated in basal conditions and after mass removal.

Results: In PHEOs, at variance with the expected reduction in metanephrines and catecholamines, no variation in body weight, blood pressure and lipid profile was observed after operation. IMT and C-IBS values in patients with PHEO were greater (at least $P<0.01$ ) than in controls. At long-term follow-up after surgery, a significant reduction in mean carotid IMT $(P<0.0009)$ and C-IBS $(P<0.009)$ values was observed. A significant correlation $(r=0.54, P<0.03)$ was found between absolute reduction in C-IBS values and absolute decrement in urinary normetanephrine levels.

Conclusions: Our study shows that normalization of catecholamine levels after the removal of PHEO improves carotid IMT and reduces carotid wall fibrosis even without influencing blood pressure and lipid profile. These findings confirm that high catecholamine tone in humans directly influences vascular remodelling of carotid arteries.
\end{abstract}

European Journal of Endocrinology 159 137-143

\section{Introduction}

Recent in vitro $(1,2)$ and in vivo $(3,4)$ studies show that catecholamines influence vascular wall growth and remodelling independently of the haemodynamic discharge. This direct trophic effect of catecholamines, mediated by $\alpha$-adrenoceptors, concerns an increase in extracellular matrix, with consequent wall fibrosis and eutrophic remodelling. Moreover, in animal models employing balloon injury of the carotid or aorta, an exacerbation of this action may be observed with proliferation, hypertrophy and migration of smooth muscle cells and adventitial fibroblasts, leading to hypertrophic remodelling $(1,4-9)$. The direct influence of sympathetic neurotransmitters on vascular wall structure has been supported by studies using $\alpha$-adrenoceptor antagonists that showed a reduction in proliferation of vascular wall cells and in neointimal growth after vascular injury (9-13). Finally, these findings have also been confirmed by the suppression in wall growth observed after local or systemic sympathetic denervation in animal experiments (14).

Studies in humans, demonstrating the role of the sympathetic activity on arterial remodelling are lacking, even if the relationship found in aging between the increments of peripheral intima-media thickness (IMT) and muscle sympathetic nerve activity seems to suggest this possibility. In addition, in patients with phaeochromocytoma (PHEO), studies conducted by micromyographic technique on the small resistance arteries have demonstrated that high catecholaminergic tone is associated with eutrophic vascular remodelling (1517). Our group recently confirmed that also in conduit arteries (carotid) of patients with PHEO a sustained vascular remodelling with fibrosis may likewise be detected, through the ultrasound and ultrasonic integrated backscatter signal (IBS) technique (18). The latter is based on an analysis of unprocessed radiofrequency signals to derive quantitative ultrasonic index. This technique has been largely utilized to evaluate collagen content of the myocardium 
extracellular matrix, which represents an important source of myocardial IBS (19), and able to differentiate normal from pathological myocardial structures $(20,21)$. Also, structural alterations of the vessel wall, such as fibrosis, calcification or deposition of lipids, may be accurately identified with this method (22). Thus, acoustic densitometry is now believed to be a clinically applicable ultrasonic backscatter imaging technology that provides an integrated online capability to measure, display and quantify the presence of fibrous tissue in intima-media complex of human arteries. This relatively simple, repeatable and quantitative analysis is able to evaluate the vascular structure in a non-invasive manner (23).

The aim of our study was to investigate, by using IBS analysis, the carotid wall characteristics of patients with PHEO before and after surgical cure.

\section{Materials and methods}

\section{Patients}

Eleven patients with PHEO $(51 \pm 13.2$ years, mean \pm S.D., range $28-58$ years) were consecutively selected for the study. The patients were recruited among those referred to our Hypertension Centre and the Endocrinological Unit of Pisa University. Diagnosis was made in all cases by standardized protocols, including hormonal, morphological (MR and scintigraphy) and, when appropriate, genetic investigations. Five patients had sporadic PHEO (two of them presenting as asymptomatic adrenal incidentalomas), three had PHEO associated with von Hippel-Lindau disease and three associated with multiple endocrine neoplasia $2 \mathrm{~A}$. The latter patients did not show hyperparathyroidism, except one who was excluded from the study since high PTH levels may per se affect the vascular wall. Thus, data of ten patients were used for the investigation. In all cases, PHEO was monolateral (right-sided in six and left-sided in four) with maximum diameter ranging from 2.8 to $4.6 \mathrm{~cm}$. No patient showed paroxysmal hypertension and none was under antihypertensive therapy because hypertension had only recently been diagnosed and blood pressure values were, on average, only slightly abnormal. This finding is only apparently surprising because of the amount of non-sporadic PHEO we studied (usually associated with normal, non-parossistic, blood pressure) may justify the observed unusual haemodynamic picture.

Ten age- and blood pressure-matched never treated consecutive subjects $(49.1 \pm 12.4$ years, mean \pm s.D., range 29-66 years) were also enrolled as a control group. Their mean blood pressure corresponded to high normal hypertension, as defined following the recent guidelines (24).

\section{Experimental design}

Clinical, hormonal and vascular investigations were performed in all subjects studied. In addition, in patients with PHEO, the analyses were repeated after surgical removal of the mass, using the laparoscopic approach. Histological examination consistently confirmed the diagnosis of PHEO. After surgery, two evaluations were performed: the first after $20.5 \pm 1.8$ months and the second after $31.5 \pm 2.2$ months. The study was approved by the local ethical committee and patients gave their informed consent.

\section{Assays}

Patients and controls, without observing a specific diet, presented in the morning $(0800$ and $0900 \mathrm{~h})$ after overnight fasting carrying $24 \mathrm{~h}$ urine collection for noradrenaline, adrenaline, normetanephrine and metanephrine determination. Then, blood samples for catecholamine measurement were taken in supine position $10 \mathrm{~min}$ after insertion of a cannula into an antecubital vein. Clinic blood pressure was measured according to the recent guidelines (at least two measurements spaced by 1-2 min, and additional measurement if the first two were quite different in patients seated for several minutes in a quiet room) by using a mercury sphygmomanometer (24). Ambulatory blood pressure monitoring was also recorded (Spacelabs Medical, Issaquah, WA, USA) in four sporadic and four syndromic PHEOs. All subjects were caffeine-, alcoholand smoking-free for at least $48 \mathrm{hrs}$ and did not assume substances or drugs affecting cardiovascular system.

Plasma catecholamines were measured by highpressure liquid chromatography (25), where intra- and inter-assay coefficients of variation were respectively $14 \%$ and $20 \%$ for noradrenaline and $17 \%$ and $22 \%$ for adrenaline. Intra- and inter-assay coefficients of variation of urinary hormones were respectively $14 \%$ and $20 \%$ for noradrenaline, $17 \%$ and $22 \%$ for adrenaline, $7 \%$ and $12.7 \%$ for normetanephrine and $18.7 \%$ and $11.9 \%$ for metanephrine (Immuno Biological Laboratories, Hamburg, Germany). Normal values in supine position in our laboratory were as follows: urinary normetanephrine $<3.27 \mu \mathrm{mol} / 24 \mathrm{~h}$, urinary metanephrine $<1.91 \mu \mathrm{mol} / 24 \mathrm{~h}$, urinary noradrenaline $<472.88 \mathrm{nmol} / 24 \mathrm{~h}$, urinary adrenaline $<109.16 \mathrm{nmol} / 24 \mathrm{~h}$, plasma noradrenaline $<2.36 \mathrm{nmol} / \mathrm{l}$ and plasma adrenaline $<0.43 \mathrm{nmol} / \mathrm{l}$.

\section{Two-dimensional conventional ultrasonography}

The study was performed using an HPSonos 5500 (Hewlett-Packard Co., Andover, MA, USA) phasedarray echograph with M-mode, two-dimensional and pulsed colour-flow Doppler capabilities. The imaging protocol involved obtaining a single longitudinal lateral view of the distal segment of the right and left common 
carotid arteries, by using a $7.5 \mathrm{MHz}$ linear array carotid probe (26). The high-resolution images were analysed to calculate IMT, defined as thickness of the vascular intima-media complex obtained in five consecutive regions of the far wall of the common carotid artery, every 4-5 $\mathrm{mm}$ beginning close to the bifurcation. The value attributed to each subject was the average value among the IMT measures, five from the left and five from the right carotid artery. Intra- and inter-observer variabilities for IMT were $4.6 \pm 0.4$ and $5.2 \pm 0.3 \%$ respectively. Mean common carotid diameter was defined as the line identifying the media-adventitia interface in the near to the far wall calculated automatically by averaging measurements at $0.1 \mathrm{~mm}$ intervals over $1 \mathrm{~cm}$.

\section{Integrated backscatter analysis (IBS)}

Ultrasonic characterization by IBS analysis of the carotid wall was performed using a special software package available as an option on the HP Sonos 5500. This system is capable of providing either conventional two-dimensional envelope-detected ultrasonographic images or IBS images in which the grey level is displayed proportional to the integrated backscattered power. A maximum of 60 frames displayed at a real-time frame rate of $30 \mathrm{~Hz}$ (30 frames/s) are captured into cine loop memory and subsequently stored on optical disk in a digital format with the same resolution as the scan converter memory $(512 \times 512,8$ bits $)$. The IBS image is internally calibrated in $\mathrm{dB}$ and has a dynamic range of $\cong 64 \mathrm{~dB}$ in the SONOS 5500 system. This system has a unique feature in which the transmit power, log compression and time-gain compensation values are displayed on a screen (and can be stored with the images), which allows an operator to adjust the system to the same values at every examination. For analysis of the image data, the IBS images were first retrieved from disk into the system memory and the analysis was performed off-line by two independent operators, blinded to the clinical characteristics of the study population. IBS values, expressed in $\mathrm{dB}$, were measured from an operator-defined region of interest (ROI) placed in the intima-media complex, in the same regions where IMT was estimated, for a total of ten measures in each subject. The system automatically calculated the average value of the IBS, which was also displayed in $\mathrm{dB}$. By adopting the adventitia as the reference object, we then corrected the IBS value (C-IBS) by subtracting the IBS value obtained from a reference ROI placed within the adventitia $(23,27)$.

\section{Reproducibility of data}

We determined intra- and inter-observer variabilities of tissue IBS values in ten randomly selected recordings twice by the same observer and once each by two independent observers. Intra-and inter-observer variabilities of IBS value were $2.6 \pm 0.8$ and $2.8 \pm$ $0.4 \%$ respectively in the experimental study.

In order to avoid bias linked to different operators or to the settings of the machine, only two operators were involved in the investigation. One performed and recorded the study and the other analysed the data while blinded to all patient information. In addition, the instrument was the same, the measurements were calibrated within the individual and, finally, apparatus settings were identical, in order to reduce extrinsic and intrinsic variability of the method.

\section{Statistical analysis}

Data were expressed as mean \pm s.E.M. One-way ANOVA was used to compare controls and patients with PHEO. To compare data before and after surgery, the paired Student's t-test was used. Linear correlation analysis was adopted to assess relationships between variables. Stepwise multiple regression analysis was carried out to test the joint effect of different variables (hormones, blood pressure, total cholesterol, low density lipoprotein and high density lipoprotein cholesterol) on IMT parameters and on C-IBS values of carotid arteries. Only clinic blood pressure, as mean values of three different recordings, was utilized for the analysis, since paroxysmal hypertension was not observed in our patients with PHEO, as confirmed by $24 \mathrm{~h}$ blood pressure measurement. Thus, the mean ( \pm s.E.M.) of S.D. of the mean $24 \mathrm{~h}$ systolic (PHEOs: $12.6 \pm$ $1.5 \mathrm{mmHg}$; hypertensives: $13.4 \pm 1.5 \mathrm{mmHg}$ ) and diastolic (PHEOs: $11.16 \pm 0.87 \mathrm{mmHg}$; hypertensives:12.1 $\pm 1.5 \mathrm{mmHg}$ ) blood pressure was superimposable in the two groups of patients. Differences were considered significant when $P<0.05$. All statistical procedures and curve fitting for linear regression analysis were performed using the StatView program (Abacus Concepts, Inc., version 4.57, Berkeley, CA, USA).

\section{Results}

Sex, age, body mass index, duration of hypertension, heart rate and lipid profile were not different in the two groups (Table 1). As expected, in patients with PHEO both plasma and urinary catecholamines and metanephrines were significantly higher than in controls (Table 2). As can be seen from Table 1, no significant variation in body weight and lipid profile was observed after the removal of the mass. Blood pressure exhibited a slight decrease after the first follow-up and a return to basal values by the end of the study. By contrast, a significant stable reduction in metanephrines and catecholamines was found after surgery (Table 2; Fig. 1).

As shown in Fig. 2, IMT in patients with PHEO $(0.88 \pm 0.06 \mathrm{~mm})$ was greater than in controls $(0.64 \pm$ $0.04 \mathrm{~mm}, P<0.01)$. After surgical cure, mean carotid 
Table 1 Demographic, haemodynamic and humoral characteristics of controls (C) and patients with phaeochromocytoma (PHEO) before and after surgical cure.

\begin{tabular}{|c|c|c|c|c|}
\hline \multirow[b]{2}{*}{ Variables } & \multirow[b]{2}{*}{ C $(n=10)$} & \multirow[b]{2}{*}{ PHEO $(n=10)$} & \multicolumn{2}{|c|}{ After surgery } \\
\hline & & & $\begin{array}{c}\text { PHEO } \\
\text { First follow-up }\end{array}$ & $\begin{array}{c}\text { PHEO } \\
\text { Second follow-up }\end{array}$ \\
\hline $\mathrm{BMI}\left(\mathrm{kg} / \mathrm{m}^{2}\right)$ & $25.7 \pm 1.7$ & $26.1 \pm 1.1$ & $24.1 \pm 1.2$ & $26.1 \pm 2.0$ \\
\hline Clinic SBP (mmHg) & $138.9 \pm 0.9$ & $138.3 \pm 5.6$ & $126.5 \pm 6.5$ & $130.3 \pm 1.7$ \\
\hline Clinic DBP $(\mathrm{mmHg})$ & $88.4 \pm 1.1$ & $87.0 \pm 4.1$ & $83.6 \pm 3.1$ & $84.7 \pm 1.5$ \\
\hline Total chol. (mmol/l) & $5.30 \pm 0.60$ & $5.35 \pm 0.24$ & $4.81 \pm 0.24$ & $5.10 \pm 0.70$ \\
\hline HDL chol. (mmol/l) & $1.52+0.40$ & $1.62+0.11$ & $1.46+0.11$ & $1.53+0.60$ \\
\hline LDL chol. ( $\mathrm{mmol} / \mathrm{l})$ & $3.30 \pm 0.18$ & $3.06 \pm 0.22$ & $2.75 \pm 0.22$ & $3.29 \pm 0.15$ \\
\hline Triglycerides (mmol/l) & $1.46 \pm 0.30$ & $1.55 \pm 0.28$ & $1.39 \pm 0.28$ & $1.42 \pm 0.19$ \\
\hline Duration of hypertension (months) & $19 \pm 8.6$ & $18 \pm 7.2$ & - & - \\
\hline
\end{tabular}

Means \pm S.E.M. are given. BMI, body mass index; SBP, systolic blood pressure; DBP, diastolic blood pressure; Chol, cholesterol.

${ }^{a}$ First follow-up, $20.5 \pm 1.8$ months; second follow-up, $31.5 \pm 2.2$ months.

IMT of PHEOs progressively decreased (first follow-up $0.86 \pm 0.06 \mathrm{~mm})$, reaching statistical significance by the end of the study (second follow-up $0.82 \pm 0.05 \mathrm{~mm}$, $P<0.0009)$. In addition, these values were significantly $(P<0.004)$ lower at the end of the study than at first follow-up. Figure 3 shows that IMT decrement after surgery occurred in all patients.

C-IBS values in PHEOs $(-21.16 \pm 0.60 \mathrm{~dB})$ were significantly greater than in controls $(-23.70 \pm$ $0.54 \mathrm{~dB}, P<0.005$; Fig. 4). After the operation, C-IBS values were already significantly lower at first follow-up $(-22.80 \pm 0.40 \mathrm{~dB}, \quad P<0.005)$ and were further reduced by the end of the study $(-23.37 \pm 0.27 \mathrm{~dB}$, $P<0.009$ ), with values similar to those found in controls (Fig. 4). Individual C-IBS reduction after surgery is shown in Fig. 5. The significant reduction in IMT and C-IBS values after surgery also maintained after adjustment for blood pressure, BMI and lipid profile values. Carotid diameter was not significantly different in controls $(5.89 \pm 0.17 \mathrm{~mm})$ and in PHEOs (5.94 \pm $0.13 \mathrm{~mm}$ ), and no change was found after surgery (first evaluation: $5.93 \pm 0.12 \mathrm{~mm}$, second evaluation: $5.92 \pm 0.15 \mathrm{~mm})$.

In PHEOs, a positive association between preoperative urinary normetanephrine levels and C-IBS values was found $(r=0.48, P<0.05)$. Furthermore, direct and significant correlation $(r=0.54, P<0.03)$ was detected between the absolute reduction in C-IBS values and the absolute decrement in urinary normetanephrine levels. No correlation was found between metanephrines and IMT or blood pressure.

\section{Discussion}

In the present study, we confirm that patients with PHEO, independently of blood pressure levels and the other cardiovascular risk factors, are characterized by an increase in carotid IMT and C-IBS values, suggesting that elevated catecholamine tone per se influences the vascular wall. Accordingly, normalization of catecholamine levels was found to be associated with an improvement in the carotid wall, giving a picture similar to that observed in controls.

A direct effect of catecholamines on the vascular wall has been reported in several in vitro $(1,2)$ and in vivo $(3,4)$ studies. They show that eutrophic (collagen deposition and fibrosis) and hypertrophic (proliferation and migration of smooth muscle cells and of adventitial fibroblasts) remodelling characterizes the damages

Table 2 Hormonal features of controls $(C)$ and of patients with phaeochromocytoma (PHEO) before and after successful surgery.

\begin{tabular}{|c|c|c|c|c|}
\hline \multirow[b]{2}{*}{ Variables } & \multirow[b]{2}{*}{ C $(n=10)$} & \multirow[b]{2}{*}{ PHEO $(n=10)$} & \multicolumn{2}{|c|}{ After surgery } \\
\hline & & & $\begin{array}{c}\text { PHEO } \\
\text { First follow-up }{ }^{\mathrm{a}}\end{array}$ & $\begin{array}{c}\text { PHEO } \\
\text { Second follow-up }{ }^{a}\end{array}$ \\
\hline Ur. Normet. $(\mu \mathrm{mol} / 24 \mathrm{~h})$ & $1.98 \pm 0.17$ & $12.41 \pm 3.97^{*}$ & $2.15 \pm 0.26^{\dagger}$ & $2.0 \pm 0.20^{\dagger}$ \\
\hline Ur. Met. $(\mu \mathrm{mol} / 24 \mathrm{~h})$ & $0.95 \pm 0.07$ & $4.79 \pm 1.69^{\star}$ & $1.12 \pm 0.30^{\dagger}$ & $1.10 \pm 0.30^{\dagger}$ \\
\hline Ur. Noradr. (nmol/24 h) & $250.4 \pm 28.6$ & $508.8 \pm 172.8^{*}$ & $423.4 \pm 139.9^{\dagger}$ & $360.6 \pm 87.4^{\dagger}$ \\
\hline Ur. Adr. (nmol/24 h) & $37.70 \pm 3.90$ & $98.66 \pm 44.64^{*}$ & $47.42 \pm 3.97^{\dagger}$ & $42.50 \pm 4.10^{\dagger}$ \\
\hline Plasma Noradr. (nmol/l) & $1.96 \pm 0.25$ & $4.29 \pm 0.90^{*}$ & $2.58 \pm 0.25$ & $2.10 \pm 0.20^{\dagger}$ \\
\hline Plasma Adr. (nmol/l) & $0.14 \pm 0.06$ & $0.97 \pm 0.51^{*}$ & $0.18 \pm 0.02^{\dagger}$ & $0.16 \pm 0.06^{\dagger}$ \\
\hline
\end{tabular}

Means \pm S.E.M. are given. Ur., urinary; Normet., normetanephrine; Met., metanephrine; Noradr., noradrenaline; Adr., adrenaline; ${ }^{\star} P<0.0001$ versus $C$; ${ }^{\dagger} P<0.05$ at least versus PHEO before surgery.

${ }^{\text {a}}$ First follow-up, $20.5 \pm 1.8$ months; second follow-up, $31.5 \pm 2.2$ months. 


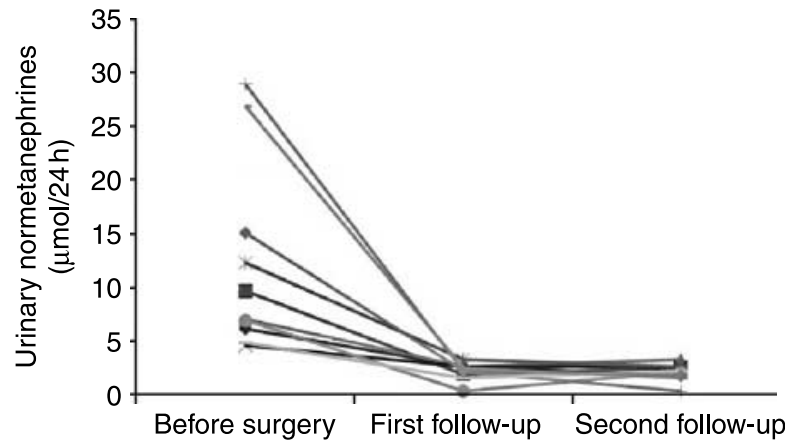

Figure 1 Individual behaviour of urinary normetanephrines after surgery in our patients with phaeochromocytoma (PHEO).

caused by catecholamines on the vascular wall (1, 4-9). These observations have also been indirectly confirmed by using $\alpha$-adrenoceptor antagonists (9-13) and by experiments in animals submitted to local or systemic sympathetic denervation (14).

In humans, even in physiological conditions, the elevated catecholaminergic tone associated with aging increases vascular (femoral) wall thickness (28). This finding has been better documented in patients with abnormal catecholamine tone due to PHEO. Thus, in small resistance arteries of these patients, eutrophic remodelling has been reported, using a micromyographic technique (15-17). In a recent study, we confirmed these data in conduit arteries (carotid) of patients with PHEO using a non-invasive procedure, such as ultrasonic backscatter signal technique (18). The latter is based on an analysis of unprocessed radiofrequency signals to derive quantitative ultrasonic index. This technique has been largely utilized to evaluate collagen content of the myocardium extracellular matrix (19-21) and recently employed to study

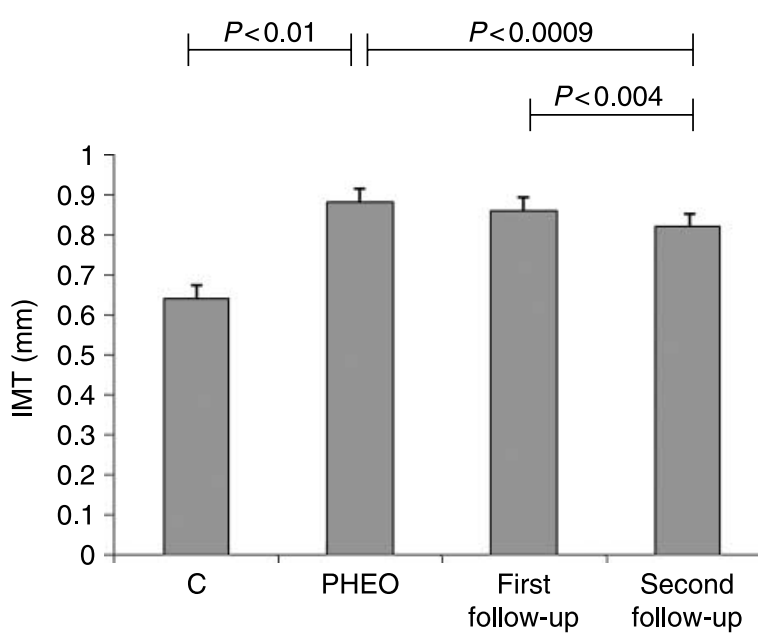

Figure 2 IMT values in controls $(\mathrm{C})$ and in patients with phaeochromocytoma (PHEO) before and after surgical treatment (first and second follow-ups). Mean \pm S.E.M. are reported.

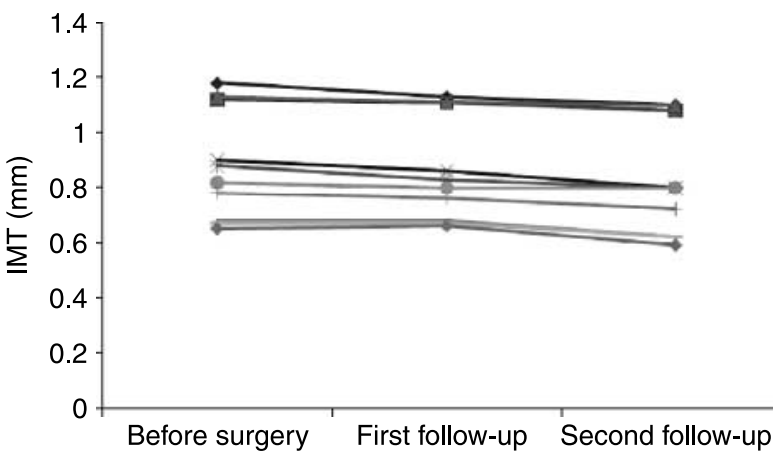

Figure 3 Individual behaviour of IMT after surgery in patients with phaeochromocytoma (PHEO).

the vascular structure of human arteries $(22,23)$. By using this method, we previously showed that carotid IMT of patients with PHEO is increased in comparison with that of essential hypertensives, independently of blood pressure values. We also reported that carotid wall thickness in patients with PHEO is sustained by collagen deposition and vascular fibrosis to a greater extent than that observed in essential hypertensives, suggesting that abnormal catecholamine levels may directly influence carotid wall remodelling in this pathological condition.

In the present study, we confirmed that patients with PHEO display increased carotid IMT and a rise in C-IBS values as compared with matched control subjects. In addition, we observed that normalization of catecholamine levels after successful removal of PHEO attenuates carotid artery IMT and reduces vascular wall fibrosis in these patients. Since blood pressure and lipid profile did not significantly change after surgery, our results seem to suggest that high catecholamine levels in humans directly influence vascular remodelling of

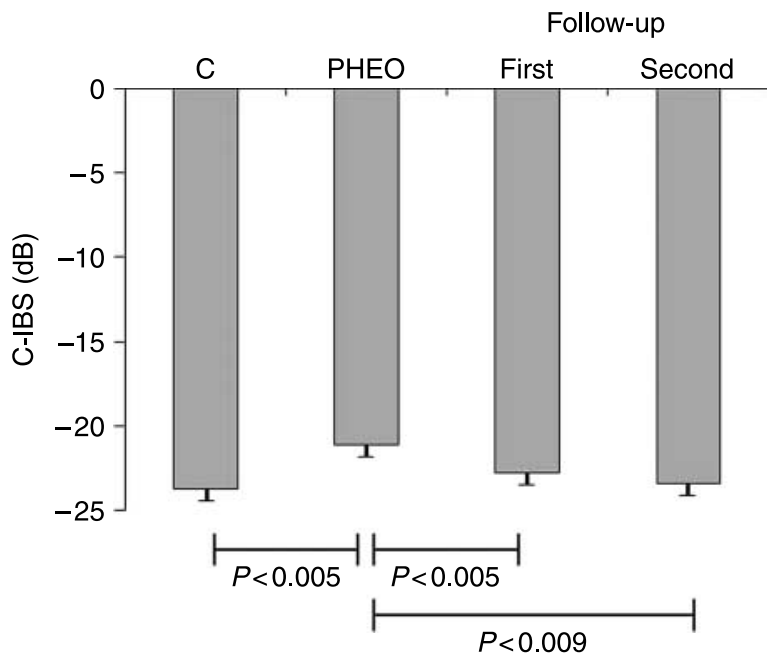

Figure $4 \mathrm{C}$-IBS values in controls (C) and in patients with phaeochromocytoma (PHEO) before and after surgery (first and second follow-ups). Mean \pm S.E.M. are reported. 


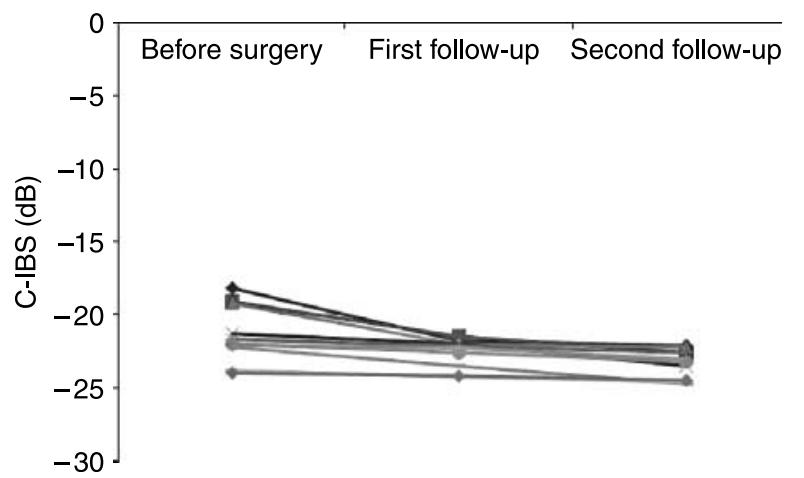

Figure 5 Individual behaviour of C-IBS values after surgery in patients with phaeochromocytoma (PHEO).

conduit arteries, independently of haemodynamic discharge and of the known factors affecting the vascular wall.

An interesting finding we observed is that IMT tended to decrease in the short term but was significantly reduced only in the long-term post-surgery period. By contrast, decrement in vascular fibrosis appeared early and was further enhanced over time, despite unchanged blood pressure. Thus, fibrosis reduction seems to be an event detectable after a few months by backscatter analysis, while vascular wall thickness reduction may be observed by conventional ultrasonography after a more prolonged period of time. This finding may explain the relationship observed only between C-IBS (but not IMT) and catecholamine reduction.

Our study population was particular, since the blood pressure of these patients was high normal $/ \mathrm{mild}$, without paroxysmal crises. The haemodynamic picture of the patients is only apparently surprising, since half of them had syndromic PHEO in which the tumour is usually poor or completely asymptomatic, while two out of five sporadic PHEOs presented as silent adrenal incidentalomas. In addition, our patients had lipid profile in the normal range. Thus, these patients did not take drugs that could possibly interfere with vascular structure, such as antihypertensive and lipid-lowering drugs. Starting from these particular clinical features, mass removal did not modify the haemodynamic and humoral parameters, except those concerning catecholamines, making plausible a direct influence of catecholamines on vascular wall. However, even whether multiple regression analysis showed that the structural changes we observed were independent of blood pressure, we are aware that the vascular haemodynamic-structural relationship is more complex than clinic blood pressure and that the small number of patients studied does not allow definitive conclusions.

Thus, in the present paper, we show that the increase in IMT and carotid vascular fibrosis of patients with PHEO is also due to a direct effect of plasma catecholamines, since their normalization is associated with an improvement in vascular structure. Therefore, our data suggest a possible role of the catecholaminergic system in the development of vascular alterations in humans.

\section{Acknowledgements}

We wish to thank Ms Emiliano Duranti for the precious technical assistance.

\section{References}

1 Zhang H \& Faber JE. Trophic effect of norepinephrine on arterial intima-media and adventitia is augmented by injury and mediated by different alpha1-adrenoceptor subtypes. Circulation Research $200189815-822$.

2 Zhang H, Facemire CS, Banes AJ \& Faber JE. Different alphaadrenoceptors mediate migration of vascular smooth muscle cells and adventitial fibroblasts in vitro. American Journal of Physiology. Heart and Circulatory Physiology 2002282 H2364-H2370.

3 Dao HH, Lemay J, de Champlain J, deBlois D \& Moreau P. Norepinephrine-induced aortic hyperplasia and extracellular matrix deposition are endothelin-dependent. Journal of Hypertension 200119 1965-1973.

4 Dao HH, Martens FM, Lariviere R, Yamaguchi N, Cernacek P, de Champlain J \& Moreau P. Transient involvement of endothelin in hypertrophic remodeling of small arteries. Journal of Hypertension $2001191801-1812$.

5 O'Callaghan CJ \& Williams B. The regulation of human vascular smooth muscle extracellular matrix protein production by alphaand beta-adrenoceptor stimulation. Journal of Hypertension 2002 20 287-294.

6 Schiffrin EL. Vascular smooth muscle growth and extracellular matrix deposition: is there a role for the sympathetic nervous system? Journal of Hypertension 200220 179-181.

7 Erami C, Zhang H, Ho JG, French DM \& Faber JE. Alpha(1)adrenoceptor stimulation directly induces growth of vascular wall in vivo. American Journal of Physiology. Heart and Circulatory Physiology 2002283 H1577-H1587.

8 Erami C, Zhang H, Tanoue A, Tsujimoto G, Thomas SA \& Faber JE. Adrenergic catecholamine trophic activity contributes to flowmediated arterial remodeling. American Journal of Physiology. Heart and Circulatory Physiology 20052222.

9 Teeters JC, Erami C, Zhang H \& Faber JE. Systemic alpha 1Aadrenoceptor antagonist inhibits neointimal growth after balloon injury of rat carotid artery. American Journal of Physiology. Heart and Circulatory Physiology $2003 \mathbf{2 8 4}$ H385-H392.

10 Fingerle J, Sanders KH \& Fotev Z. Alpha 1-receptor antagonists urapidil and prazosin inhibit neointima formation in rat carotid artery induced by balloon catheter injury. Basic Research in Cardiology 199186 75-81.

11 Jackson CL, Bush RC \& Bowyer DE. Inhibitory effect of calcium antagonists on balloon catheter-induced arterial smooth muscle cell proliferation and lesion size. Atherosclerosis $1988 \quad 69$ $115-122$.

12 O'Malley MK, McDermott EW, Mehigan D \& O'Higgins NJ. Role for prazosin in reducing the development of rabbit intimal hyperplasia after endothelial denudation. British Journal of Surgery 198976 936-938.

13 Vashisht R, Sian M, Franks PJ \& O'Malley MK. Long-term reduction of intimal hyperplasia by the selective alpha-1 adrenergic antagonist doxazosin. British Journal of Surgery 1992 79 1285-1288.

14 Head RJ. Hypernoradrenergic innervation and vascular smooth muscle hyperplastic change. Blood Vessels 199128 173-178. 
15 Rizzoni D, Muiesan ML, Porteri E, Salvetti M, Castellano M, Bettoni G, Tiberio G, Giulini SM, Monteduro C, Garavelli G \& Agabiti-Rosei E. Relations between cardiac and vascular structure in patients with primary and secondary hypertension. Journal of the American College of Cardiology 199832 985-992.

16 Rizzoni D, Porteri E, Castellano M, Bettoni G, Muiesan ML, Muiesan P, Giulini SM \& Agabiti-Rosei E. Vascular hypertrophy and remodeling in secondary hypertension. Hypertension $1996 \mathbf{2 8}$ 785-790.

17 Porteri E, Rizzoni D, Mulvany MJ, De Ciuceis C, Sleiman I, Boari GE, Castellano M, Muiesan ML, Zani F \& Rosei EA. Adrenergic mechanisms and remodeling of subcutaneous small resistance arteries in humans. Journal of Hypertension $2003 \mathbf{2 1}$ 2345-2352.

18 Bernini G, Franzoni F, Galetta F, Moretti A, Taurino C, Bardini M, Santoro G, Ghiadoni L, Bernini M \& Salvetti A. Carotid vascular remodeling in patients with pheochromocytoma. Journal of Clinical Endocrinology and Metabolism 200691 1754-1760.

19 Hall CS, Scott MJ, Lanza GM, Miller JG \& Wickline SA. The extracellular matrix is an important source of ultrasound backscatter from myocardium. Journal of the Acoustical Society of America 2000107 612-619.

20 Miller JG, Perez JE \& Sobel BE. Ultrasonic characterization of myocardium. Progress in Cardiovascular Diseases 198528 85-110.

21 Perez JE, Barzilai B, Madaras EI, Glueck RM, Saffitz JE, Johnston P, Miller JG \& Sobel BE. Applicability of ultrasonic tissue characterization for longitudinal assessment and differentiation of calcification and fibrosis in cardiomyopathy. Journal of the American College of Cardiology $1984 \mathbf{4} 88-95$.

22 Lee RT, Grodzinsky AJ, Frank EH, Kamm RD \& Schoen FJ. Structure-dependent dynamic mechanical behavior of fibrous caps from human atherosclerotic plaques. Circulation $1991 \mathbf{8 3}$ 1764-1770.

23 Takiuchi S, Rakugi H, Honda K, Masuyama T, Hirata N, Ito H, Sugimoto K, Yanagitani Y, Moriguchi K, Okamura A, Higaki J \& Ogihara T. Quantitative ultrasonic tissue characterization can identify high-risk atherosclerotic alteration in human carotid arteries. Circulation $2000 \mathbf{1 0 2}$ 766-770.
24 Mancia G, De Backer G, Dominiczak A, Cifkova R, Fagard R, Germano G, Grassi G, Heagerty AM, Kjeldsen SE, Laurent S, Narkiewicz K, Ruilope L, Rynkiewicz A, Schmieder RE, Boudier HA, Zanchetti A, Vahanian A, Camm J, De Caterina R, Dean V, Dickstein K, Filippatos G, Funck-Brentano C, Hellemans I, Kristensen SD, McGregor K, Sechtem U, Silber S, Tendera M, Widimsky P, Zamorano JL, Erdine S, Kiowski W, Agabiti-Rosei E, Ambrosion E, Lindholm LH, Manolis A, Nilsson PM, Redon J, Viigimaa M, Adamopoulos S, Bertomeu V, Clement D, Farsang C, Gaita D, Lip G, Mallion JM, Manolis AJ, O’Brien E, Ponikowski P, Ruschitzka F, Tamargo J, van Zwieten P, Waeber B \& Williams B. ESH/ESC 2007 Guidelines for the management of arterial hypertension. Revista Española de Cardiología 200760 968.e1-94.

25 Krstulovic AM, Dziedzic SW, Bertani-Dziedzic L \& DiRico DE. Plasma catecholamines in hypertension and pheochromocytoma determined using ion-pair reversed-phase chromatography with amperometric detection: investigation of the separation mechanism and clinical methodology. Journal of Chromatography 1981217 523-537.

26 Pignoli P, Tremoli E, Poli A, Oreste P \& Paoletti R. Intimal plus medial thickness of the arterial wall: a direct measurement with ultrasound imaging. Circulation 198674 1399-1406.

27 Kawasaki M, Takatsu H, Noda T, Ito Y, Kunishima A, Arai M, Nishigaki K, Takemura G, Morita N, Minatoguchi S \& Fujiwara H. Noninvasive quantitative tissue characterization and two-dimensional color-coded map of human atherosclerotic lesions using ultrasound integrated backscatter: comparison between histology and integrated backscatter images. Journal of the American College of Cardiology 200138 486-492.

28 Dinenno FA, Jones PP, Seals DR \& Tanaka H. Age-associated arterial wall thickening is related to elevations in sympathetic activity in healthy humans. American Journal of Physiology. Heart and Circulatory Physiology 2000278 H1205-H1210.

Received 8 May 2008

Accepted 12 May 2008 